\title{
CRIAÇÃO DE BANHEIROS LGBTS: inclusão ou prática discriminatória?
}

\section{1- Elisângela Domingues Michelatto Natt*}

Doutoranda, Universidade Federal de Minas Gerais, Brasil.

Centro de Pós-Graduação e Pesquisas em Administração - Universidade Federal de Minas Gerais, Brasil. elisdomingues@gmail.com

\section{2- Luiz Alex Silva Saraiva}

Doutor, Universidade Federal de Minas Gerais, Brasil.

Centro de Pós-Graduação e Pesquisas em Administração - Universidade Federal de Minas Gerais, Brasil. saraiva@face.ufmg.br

http://lattes.cnpq.br/8812184151373749

\section{3- Alexandre de Pádua Carrieri}

Doutor, Universidade Federal de Minas Gerais, Brasil.

Centro de Pós-Graduação e Pesquisas em Administração - Universidade Federal de Minas Gerais, Brasil. alexandre@face.ufmg.br

http://lattes.cnpq.br/0555523196295968

\section{Editor responsável pela submissão:}

Diego Maganhotto Coraiola.

Artigo analisado via processo de revisão duplo cego (Double-blind).

Recebido em: 17/07/2014

Aprovado em: 10/10/2014

Última Alteração: 24/06/2016

* Contato Principal: Av. Antonio Carlos, 6627, Pampulha. Universidade Federal de Minas Gerais, Faculdade de Ciências Econômicas. Belo Horizonte - MG. CEP: 31270-901. 


\title{
CRIAÇÃO DE BANHEIROS LGBTS: INCLUSÃO OU PRÁTICA DISCRIMINATÓRIA?
}

\section{RESUMO}

O objetivo neste artigo é problematizar o papel das organizações na multiplicação de práticas discriminatórias, bem como refletir sobre o envolvimento e a reação das comunidades que representam as minorias que sofrem discriminação. A violência simbólica é uma das formas mais cruéis de segregação e discriminação, ainda mais quando mascarada por "boas intenções". No estudo se analisou a instalação de banheiros LGBTs em uma quadra de uma escola de samba, em uma feira agropecuária e em uma escola de ensino médio. Partiu-se do conceito desenvolvido por Augé (1994), sobre os não lugares, como se tratando de espaços exclusivos e neutros, embora tal neutralidade não se verifique na dinâmica social. As conclusões sugerem que os não lugares são apenas ideais, já que nem mesmo os banheiros escapam da dinâmica simbólica envolta e, ao mesmo tempo, imbricada nas relações sociais.

Palavras-chave

Inclusão; Discriminação; Violência simbólica; Não lugares; Banheiros.

\section{CREATION OF LGBTS BATHROOMS: INCLUSION OR DISCRMINATORY PRACTICE?}

\begin{abstract}
In this paper we discuss the role of organizations in the reinforcement of discriminatory practices, as well we reflect about the evolvement and reaction of minorities who suffer discrimination. Symbolic violence is one of the cruelest forms of segregation and discrimination, even more when it is masked through "good intentions". In this study we have analyzed the installation of LGBTs' bathrooms in a block of a samba school, in an agricultural fair, and in a high school. We based our discussion on Augé's concept of non-place (1994), as exclusive and neutral spaces, although this neutrality is not perceived in social dynamics. Conclusions suggest that non- places are just ideal places, where not even bathrooms elude of symbolic dynamics that are, also, surrounded and imbricated in social relations.
\end{abstract}

\section{Keywords}

Inclusion; Discrimination; Symbolic violence; Non places; Bathrooms. 


\section{Introdução}

No intuito de discutir sobre as práticas discriminatórias, bem como provocar a reflexão sobre o limiar entre inclusão e discriminação social, buscou-se compreender como a questão da criação de banheiros específicos para a utilização de lésbicas, gays, bissexuais e transgêneros (LGBT) vêm sendo veiculada e discutida na mídia eletrônica, mais especificamente na internet. Não houve a intenção de esgotar o tema, mas sim de incitar maiores discussões sobre a questão, que parece tão distante dos círculos intelectuais.

Para embasar a discussão recorreu-se ao conceito de não lugar, desenvolvido por Marc Augé (1994). De acordo com o autor, os não-lugares são produtos específicos da contemporaneidade e opõem-se aos lugares em que os nativos vivem, celebram sua existência, constituem as famílias tradicionais, trabalham e até mesmo guardam as suas fronteiras. Em outras palavras, o não lugar é ou deveria ser considerado neutro, longe das formatações sociais e culturais. Banheiros seriam então um exemplo de espaços que constituídos como não lugares, pois não cumpririam, em princípio, nenhum dos critérios que caracterizam o lugar no sentido antropológico, isto é, o lugar em que os indivíduos se expressam ou se socializam.

No entanto, observou-se que a criação dos banheiros LGBT em espaços públicos como bares, restaurantes, quadras de samba e feiras agropecuárias, pautada na ideologia de uma opção a mais para um não lugar, vai por si só contra toda a proposta do que seriam os não lugares. Notou-se que essa prática se constitui como algo que, se não objetiva a segregação, acaba por contribuir com ela. Dizer que há um lugar exclusivo para a comunidade LGBT é o mesmo que dizer que essas pessoas não são como as demais e, portanto, precisam ser excluídas dos ambientes comuns aos heterossexuais.

Os eventos que impulsionaram a discussão que segue foram apresentados na mídia como grandes acontecimentos, ao mesmo tempo em que suscitou críticas das comunidades que defendem os direitos iguais para as minorias relacionadas à questão da sexualidade e, principalmente, da diferença sexual. O primeiro caso é a instalação de um terceiro banheiro na quadra da escola de samba Unidos da Tijuca. O segundo trata-se da instalação de banheiros para homossexuais em uma feira agropecuária e, por fim, a instalação de um terceiro banheiro em uma escola do ensino médio, tradicional em uma cidade do interior do Estado do Paraná. Apresentam-se ainda, de forma complementar, argumentos relacionados ao projeto de lei para a criação de banheiros para gays na cidade de São Paulo.

No intuito de clarificar a ordem dos argumentos, bem como as análises realizadas a partir do tema proposto, o desenvolvimento do artigo partiu de uma breve introdução ao tema, seguindo-se da apresentação do conceito de não lugar e, por consequência, apresenta-se a dicotomia lugar - não lugar. Posteriormente, discorre-se de forma sucinta, sobre o conceito de violência simbólica, passando para a apresentação do percurso metodológico com relatos e análises de alguns casos de criação de banheiros dedicados exclusivamente ao uso da comunidade LGBT. Por fim, são desenvolvidas algumas breves considerações sobre o conflito observado.

\section{O Conceito de Não Lugar}

A partir das considerações de Augé (1994), a definição de lugar remete a um espaço escolhido por nossos ancestrais sociais para que nós, seus descendentes, pudéssemos nos relacionar com o mundo a partir de padrões e regras previamente estabelecidos e que, para a sociedade dominante, deveria instaurar a ordem. Trata-se de um espaço a ser defendido, tendo sempre um princípio de sentido no qual, aqueles que o habitam desenvolvem a inteligibilidade necessária para a articulação das ações, de tal forma que elas façam sentindo para quem o observa. Ou seja, sua existência e seus modos, costumes e crenças fazem sentido e têm razão de ser a partir de um lugar, que é identitário, relacional e histórico (Augé, 1994).

O que incomoda nessa definição é que existiriam então, os não lugares. Em outras palavras, parte-se do princípio de que há lugares que se esvaem dessas condições e subjetivações da vida social. Banheiros e meios de transporte coletivos poderiam ser exemplos de não lugares, já que ambos nos servem apenas para uma circunstância instrumental, pois a utilização de ambos teria então um caráter meramente funcional, prático. Não seria provável que nesses lugares houvesse qualquer espaço para subjetivações, interações sociais ou mesmo qualquer transmissão ou reificação de códigos para a vida social. Contudo, o que se observa é exatamente o contrário, pois é nos lugares menos prováveis, sob a ótica dos não lugares, que regras são mais fortemente estabelecidas e que os assuntos mais delicados parecem proliferar. 
Assim, os lugares de nascimento, que são muito além dos lugares no sentido geográfico, são os responsáveis pela construção de identidades, instituindo regras de residência e de convívio social. Existem como formas de inscrição objetiva, as quais buscam delimitar a constituição dos sujeitos a partir de referências compartilhadas que designam fronteiras e marcam as relações entre os indivíduos e grupos. Nesse sentido, os espaços sociais são sempre uma construção histórica, passada de geração a geração a fim de perpetuar regras e costumes sociais considerados os mais adequados em nome de uma ordem fictícia (Mendes, 2011).

Em oposição a esse conceito de lugar, no sentido antropológico, Augé (1994) descreve os não lugares como não sendo definidores de identidade, ou nem mesmo espaços relacionais ou históricos. O autor é ainda mais enfático ao pontuar que nesses não lugares, o caráter provisório e efêmero, é comprometido ou afinado com a transitoriedade e com a solidão. Nesse sentido, autores como Silva e Brasil (2010) retomam a ideia de Augé (1994) de que os não-lugares são a medida de uma época, caracterizada pelo excesso factual, pela superabundância espacial e pela individualização das referências. Essa dualidade, que na verdade parece complementar, constitui-se como um objeto inerente a contemporaneidade e, que deve ser estudada em suas contradições e complexidades, e não apenas como simples oposição a uma modernidade perdida. Talvez resida aí o ponto principal envolvendo a questão dos não lugares.

Carvalho (2005) aponta que para construir o conceito de não lugar, Augé parte da ideia de que a primeira transformação de uma chamada supermodernidade estaria relacionada ao tempo, particularmente a partir do século XX, no período em que ocorreram as guerras mundiais, pautadas em ideais totalitaristas que ocasionaram descrença em narrativas e sistemas de interpretação que até então se demonstravam válidas. Esse questionamento ou a incitação de questionamentos dessa ordem colocaram em dúvida a história como a grande e legitimada detentora do sentido da evolução da humanidade, o que permitiu uma significativa alteração da percepção do tempo e no uso e disposição que fazemos dele.

Outro argumento apresentado por Carvalho (2005) é o de que a transformação acelerada do espaço se manifesta por causa da necessidade de encolhimento das distâncias, o que requer transporte rápido, comunicação de qualidade, mesmo em longas distâncias, produção de imagens em tempo real e manipulação de informações que, ao mesmo tempo em que exercem influência em mensagens objetivas, excedem-nas ao ponto de tronarem-se descoladas e portadores de verdades próprias. Esse argumento poderia levar a concluir que espaços virtuais, por exemplo, estariam esvaziados de sentido cultural ou social, como se constituíssem uma espécie de lugar neutro em que, tendo liberdade para ser eu mesmo, descolaria minhas ações das convenções e da ordem social. Contudo, não estaria esse não lugar, imbricado de questões de toda uma geração, transformações nas formas de sentir e relacionar-se? Da mesma forma, segue a questão, não seriam os tais não lugares o espaço mais propício às manifestações de sentido e de libertação das convenções e, por conseguinte, o lugar mais puro da manifestação social? Parece confuso, mas desenvolverei esse argumento mais adiante.

Se esses lugares (não lugares) são necessários à circulação acelerada das pessoas e produtos, regra de uma contemporaneidade (Augé, 1994), eles não seriam por si só um produto da realidade social, das novas necessidades culturais e econômicas? Isso não faria, por si só, uma ponte com o lugar no sentido antropológico? Pois bem, parece não haver muito sentido nesse argumento de não lugar. Pois as próprias famílias não são mais as mesmas, a forma como os filhos da contemporaneidade são criados e educados não é mais a mesma, a casa não tem mais o mesmo apelo que tinha décadas atrás. Isso tudo leva ao questionamento sobre o quanto estamos submersos em cultura e regras sociais mesmo ao usar um aparentemente simples e inofensivo banheiro. Estaríamos livres das convenções e limitações instituídas nos lugares de nascença ao nos observarmos em um não lugar? Estariam, como afirma Augé (1994), os não lugares livres da cultura localizada no tempo e no espaço? Parece quase impossível essa neutralidade.

Com o advento da nova concepção de tempo, pessoas interagem e deixam muito de si em aeroportos, terminais rodoviários, trens, ônibus, aviões, banheiros, supermercados, salões de beleza e em uma infinidade de lugares que poderiam ser considerados exclusivamente como locais de passagem, rápida e imediata. Pode parecer radical, mas com a velocidade que o mundo contemporâneo requer, o argumento de Augé (1994) parece ter sentido completamente inverso. Em outras palavras, é justamente o que ele aponta como sendo os legitimadores da existência dos não lugares, o elemento responsável por criar novos lugares de interação social, que o tempo, ou a falta dele, faz com que cada lugar seja a expressão de uma época, de uma cultura ou de valores socialmente compartilhados. Nesse sentido, observa-se que a discussão sobre os banheiros destinados à comunidade LGBT nos fornece subsídios interessantes para a discussão de que, de fato, não há os tais não lugares, isentos e neutros, tanto em termos históricos quanto culturais. 
Nesses lugares, ou a partir deles, pode-se notar as mais variadas formas de manifestações sociais como, por exemplo, a violência simbólica, questão que apresento a seguir.

\section{Violência Simbólica}

A violência simbólica constitui um tema ainda pouco explorado, tênue e desconhecido. Um tipo de violência que somente é exercida de forma dissimulada. Nessa forma simbólica, os modos de dominação não requerem força física, mas exploram o caráter arbitrário e mágico das representações coletivas. Esse tipo de violência simbólica é exercido a partir da compreensão da lógica de funcionamento das relações sociais, bem como da inteligibilidade das formas de manutenção das estruturas objetivas e subjetivas do mundo social. Há autores, como Bourdieu (2008a), que apontam que a posição ocupada pelos dominantes na estrutura possibilita a veiculação de estratégias que visam conservar a posição ocupada, perpetuando assim o status quo e possibilitando a continuidade dos princípios de dominação.

Ainda de acordo com o mesmo autor, a violência simbólica é mais presente na medida em que é mascarada, pois sob um discurso de inclusão, por exemplo, estabelece-se formas de violência quase que incontestáveis, pois torna-se extremamente difícil defender-se do que, em um primeiro momento, parece-nos benéfico. Ao não esbarrar na reprovação coletiva, cria-se uma possibilidade de violência aparentemente branda, em que aqueles que a exercem precisam estar cautelosamente engajados, mesmo que inconscientemente, sob a ótica da dissimulação, pois é preciso doar-se a ponto de articular ações que pareçam benéficas e de bom tom. Esse doar-se à causa da manutenção do poder requer dos sujeitos uma articulação por meio da qual as relações arbitrárias são transformadas em relações legítimas.

Nesse contexto, políticas identitárias são como máquinas ideológicas, que de acordo com Bourdieu (2009a), promovem uma dinâmica social na qual os grupos dominantes institucionalizam sua autoridade, tentando evitar ou amenizar conflitos possíveis ou prováveis. Ao evitar os conflitos, permite-se o exercício do poder de forma branda, quase que invisivelmente, porém, fortemente sentida. Essa maneira perversa de dominação, por meio dos sistemas simbólicos, é capaz de operar de forma sistemática e consistente o processo de favorecimento e cumprimento dos interesses de grupos mais fortes política ou socialmente, em detrimento dos interesses das minorias (Foucault, 2000).

As formas de dominação exercidas na sociedade moderna, por meio da distinção (Bourdieu, 2008a), da arte (Bourdieu, 2008b), da política (Bourdieu, 2009a, 2009c) e de todas as formas de política identitárias, demonstra o caráter universal dos sistemas simbólicos. Para Foucault (2000), esse tipo de violência é capaz de se repetir, mesmo que sob o véu da particularidade, nas mais diversas organizações sociais, sob as mais variadas formas de dissimulação e de distorção dos verdadeiros sentidos e valores. Ao não ter do que se defender, é comum alienar-se da realidade, é comum estagnar-se, ou mesmo replicar as práticas discriminatórias de violência.

Considerar-se diferente do que se é realmente, ou mesmo não ter consciência da própria diferença, permite que os detentores ou usurpadores do poder não sejam simplesmente cínicos calculadores que enganam conscientemente os demais (Teles, 2012). Há, nos casos de dominação e repressão das minorias, o que Bourdieu (2009b) definiu como uma espécie de postura ilegítima em que o conjunto dá mais valor aos que Ihe dão valor. Em outras palavras, podem existir ações discriminatórias que são tão sutis que cooptam sujeitos das minorias a falarem em prol da própria estratégia de dominação, permitindo-se não apenas serem mais facilmente dominados, mas também tornarem-se elementos da própria manipulação e violência simbólica.

Talvez um dos pontos que tornam a subversão mais complexa e por isso difícil de se praticar seja o fato de que ela mesma faz daquilo que é instituído, um elemento de conservação. Pois não raro, se observam grupos ora dominados aderirem ao poder e cometerem tudo aquilo que sempre combateram. Trata-se sempre de uma busca incessante em conservar as vantagens associadas a um estado anterior de instituição. Talvez um bom exemplo desse fenômeno seja a própria ação de dominação observada nos micro espaços sociais entre as parcelas dominadas. No exemplo dado por Bourdieu (2009b), os intelectuais proletaróides seriam perigosos e nocivos, na medida em que, ao mesmo tempo em que combatem e criticam as formas de dominação, estão ávidos por uma brecha que os possibilite acesso ao domínio, que se daria fortemente pautado por ressentimentos.

Em um cenário denso, de relações conflituosas envolvendo as regras de poder e dominação simbólica, resta a tentativa de estabelecimento da verdade imanente das lutas no interior de cada situação conflituosa. Essa verdade apenas poderia ser acessada ao se apreender a lógica objetiva segundo a qual seriam determinadas as estratégias de dominação e subversão. Seria preciso 
perceber e compreender as estratégias de desmobilização das parcelas dominadas, bem como se livrar das crenças que permitem a legitimação da ordem arbitrariamente estabelecida e que faz com que sejam incorporadas ações de violência e discriminação como questões naturais, tornando-as invisíveis (Teles, 2012).

Considerando a necessidade de desvelar a dominação simbólica e promover a reflexão e possibilidade de subversão da ordem dominante, é preciso assumir que os sujeitos sentem, pensam e agem conforme e a partir do lugar em que são inseridos socialmente. Aliando esse aspecto ao conceito de não lugar, observa-se a dificuldade em limitar ou definir o que seriam os não lugares. Pois, se é a partir da perspectiva dos dominantes que os indivíduos sentem e agem e se a violência simbólica é possível a partir da incorporação do ambiente em diferentes graus de consciência, infere-se que cada lugar (não lugar) poderia, em maior ou menor medida, influenciar os graus de dominação.

Para Teles (2012) a extensão dessa violência envolve o corpo e a forma como os indivíduos interagem uns com os outros. As formas como eles vêem e apreendem a própria vida está imbricada nas estruturas que produzem e reproduzem rótulos para ambos os sexos. Assim, a submissão, tanto objetiva quanto subjetiva, estaria sempre em conjunção com a objetividade das estruturas sociais. Poder-se-ia encontrar então, nos elementos mais aparentemente inofensivos, a naturalização de estratégias de dominação e a apreensão cognitiva que promove a incorporação de uma identidade social associada a um corpo. Nas formas mais sutilmente implantadas na sociedade, como no exemplo dos não lugares, haveria a perpetuação do status quo, influenciando a percepção de si mesmo perante o mundo.

A autora é ainda mais enfática ao dizer que as ações que constituem o dia a dia, além de serem automaticamente reproduzidas, reforçam a crença de que existem não lugares. Mesmo que pouco ou nada se conheça sobre o conceito de Augé (1994), as pessoas são tentadas o tempo todo a crerem que há espaços nos quais são todos naturalmente iguais e que a reflexividade não se faz necessária em certas circunstâncias. Esquece-se muitas vezes, porém, que há espaços entre a incorporação das regras e das ações e aí pode-se instigar a capacidade de refletir sobre as condições de vida e mesmo sobre as possibilidades de mudança. Para Teles (2012) o que ocorre é que há uma limitação na compreensão do mundo onde as atualizações ocorrem de tal forma que possibilitam que os limites sociais sejam repensados.

Teles (2012) corrobora com essa inferência, ao observar que os indivíduos são objetivados naquilo que é mais real, mais concreto. De acordo com a autora, a maior parte de todo aprendizado de si ocorre a partir das representações que os outros têm em relação a cada um de nós, ao mesmo tempo em que, havendo capacidade cognitiva, é possível recuperar algo em si mesmo a partir da visão do outro. Partindo-se dessa observação, percebe-se a possibilidade de construção de espaços de negociação, resistência e mudança nos espaços menos prováveis, o que desconstruiria o conceito de não lugar, proposto por Augé (1994).

Ainda conforme aponta Teles (2012), a elasticidade do potencial reflexivo da ação contida na vida diária varia na medida em que se possa proceder a alguma forma de individuação. Contudo, mesmo em lugares tão ermos ou neutros, poderia haver forma de reflexão, mesmo que com nenhuma ou pouca interação direta com outros sujeitos. Questões sobre si próprios, sobre relacionamentos sociais e mesmo sobre todo o contexto em que se está inserido podem levar a ganhos de autonomia ou mesmo de perdas relacionadas a aceitação social.

Nesse sentido, é de suma relevância retomar o alerta feito por Bourdieu (2009a), de que é preciso saber notar o poder onde ele menos de deixa perceber, onde ele passa incólume. Para o autor, esse poder simbólico, quase invisível e exercido com a cumplicidade dos que não querem saber que estão sujeitos a ele, tende a estabelecer uma ordem baseada no totalitarismo, na doutrina sutil, porém não menos dolorosa. O poder simbólico é, para Bourdieu (2009a), uma arma poderosa, que contribui para a integração real da classe dominante e para a integração fictícia da sociedade em seu conjunto. É algo que promove uma falsa consciência.

Considerando as particularidades do poder simbólico, bem como as questões envolvendo o conceito de não lugar e as formas de objetivação e subjetivação da violência simbólica, partiu-se do exposto até aqui no intuito de estabelecer uma análise coerente sobre as circunstâncias envolvendo a criação dos banheiros destinados à comunidade LGBT. Para que a intenção e a trajetória realizada na pesquisa sejam compreendidas, apresenta-se a seguir o percurso adotado para a realização da pesquisa e análise. 


\section{O Caminho Percorrido}

Esse artigo é o resultado da experiência e participação em uma disciplina ofertada no Centro de Pós-Graduação e Pesquisas em Administração da Universidade Federal de Minas Gerais. A discussão aqui apresentada surgiu em uma das aulas em que se discutia a questão de gênero e foi desenvolvida em aulas posteriores, como a que tratava da questão dos poderes. A partir das discussões, instaurou-se a busca por conhecer um pouco mais sobre os episódios envolvendo a questão da instalação dos banheiros para a comunidade LGBT. Inicialmente buscou-se conhecer cada um dos episódios. Foram acessadas algumas matérias sobre os eventos e a partir delas foi-se em busca de informações que revelassem um pouco sobre os impactos da instalação de terceiros banheiros em ambientes públicos.

As informações foram obtidas a partir de sites que disponibilizavam as matérias apontando o impacto e as respostas da comunidade de forma geral, principalmente a comunidade LGBT. Foram encontrados 14 sites que apresentavam os acontecimentos e as discussões suscitadas a partir deles. Os eventos relacionados referem-se à criação de banheiros para lésbicas, gays, bissexuais e transgêneros. O primeiro evento é a instalação de um terceiro banheiro na quadra da escola de samba Unidos da Tijuca, em janeiro de 2011. Em fevereiro de 2012, dois outros eventos relacionados à criação de um banheiro específico para a comunidade LGBT tomaram as manchetes. O primeiro foi o caso de um Colégio no interior do Estado do Paraná, na cidade de Londrina, em que o diretor decidiu instalar um terceiro banheiro; o segundo foi a proposta de instalação desses banheiros em uma feira agropecuária no Estado do Acre. Em julho de 2012, mais uma polêmica envolvendo a criação dos banheiros coloridos, como denominados pela mídia. Tratava-se agora de um projeto de lei, proposto por um vereador na cidade de São Paulo, para que houvesse a instalação de banheiros específicos para a comunidade LGBT em locais públicos.

As análises e discussões foram baseadas em questionamentos sobre o poder e a dominação simbólica, bem como na natureza dos argumentos elencados em cada um dos casos mencionados. O trabalho tem natureza qualitativa e apresenta um com corte transversal (Vieira, 2004). As atividades relacionadas ao seu desenvolvimento ocorreram em um momento específico, no primeiro quadrimestre do ano de 2013, remetendo-se às informações que remetem a eventos ocorridos entre 2011 e 2012. A opção em realizar a pesquisa de característica qualitativa deve-se ao fato de que a mesma está baseada na interpretação dos fenômenos observados, o que resulta na atribuição de significados, sempre considerando o ambiente em que os mesmos foram constituídos.

Os procedimentos aqui utilizados, característicos da pesquisa social, visam instaurar o questionamento investigativo, proporcionando o desvelar da realidade observada (Minayo, 1994). As possibilidades de reflexão acerca dos fenômenos frente à realidade e o desenvolvimento da dinâmica social permitem identificar as preocupações e interesses que perpassam o meio social. Faz de suma importância, contudo, ressaltar que a presente pesquisa retrata um recorte particular de uma discussão muito abrangente, portanto, trata-se de um ponto de vista limitado a um fenômeno específico, mas que remete a questões muito mais profundas. No intuito de clarificar a intenção que constitui os argumentos aqui apresentados, faz-se necessário apontar que a questão dos banheiros é apenas um pequeno indício da questão da violência em relação às minorias, bem como se trata apenas de mais uma forma de utilização de dispositivos aparentemente inofensivos, para perpetuar crenças e valores cruéis, de forma dissimulada e nem por isso, menos violenta.

Foram analisadas as circunstâncias que levaram às propostas de instalação dos terceiros banheiros, bem como os discursos imbricados na assumida intenção de inclusão. Levou-se em consideração tanto as características peculiares a cada situação quanto o público diretamente atingido com as propostas. Observou-se nas falas dos idealizadores dos projetos, uma distância clara em relação ao que os representantes das comunidades LGBT argumentavam sobre os fatos. Embora em muitos momentos ambos parecessem falar sobre a mesma coisa e o mesmo lugar, percebeu-se uma dicotomia gigantesca entre o discurso de inclusão e as verdadeiras intenções.

Durante todo o processo de tentativa de entendimento sobre o tema, remeteu-se à reflexão qual o caminho mais adequado a se percorrer, no entanto, nos pareceu pouco provável que exista um caminho que fosse tão seguramente o mais adequado. O mergulho nas questões expostas pelos dois lados de toda a situação da criação dos banheiros - criadores e atingidos ou beneficiados permitiu compreender a importância das políticas públicas no delineamento dos direitos humanos e na conservação de valores e reificação das forças simbólicas que perpassam a realidade. Contudo, sente-se a necessidade de avançar sobre as questões envolvendo a discussão de gênero, pois esta constitui-se como uma limitação do trabalho, já que não encontramos espaço, nesse momento, para tratar mais cuidadosamente da questão. 
Ao desenvolver o processo de análise, algumas interpretações foram possíveis a partir dos preceitos do conceito de não lugar, porém, muito mais no sentido de questionar o conceito do que reafirmá-lo. Também recorremos à questão da violência e do poder simbólico, por acreditar-se que esses dois aspectos estão imbricados na questão dos banheiros para homossexuais. Apresentou-se ainda, alguns elementos importantes sobre a questão da sexualidade e do direito de exercer a diferença, bem como a distorção de valores morais que perpassam a sociedade contemporânea. Nossos argumentos e observações pautaram-se na ideia de Santos (2000), de que se faz fundamental a utilização e observação de qualquer elemento que registre informações relevantes para a adequada elaboração de uma pesquisa.

Em suma, o estudo se pautou em uma coleta baseada em pesquisas documentais e observação das notícias veiculadas pela mídia eletrônica, o que resultou em uma análise que considerou a dinâmica simbólica envolvendo a criação dos banheiros, bem como a atenção dada a questão e a divergência de conformidade entre a disponibilização desses espaços e a aceitação por parte dos possíveis usuários. Vale ressaltar ainda que o trabalho esteve fundado na proposta de Lüdke e André (1986), de que a investigação de fontes escritas revela elementos identificáveis a partir de questões relevantes à pesquisa. Por se tratar de uma pesquisa qualitativa, foi permitida uma análise pontual sobre a dinâmica da criação dos banheiros, partindo de nossas posições e condições de análise, o que resultou em uma observação crítica, a partir de um ponto de vista.

Percebeu-se a opção apresentada como a mais indicada, por encontrar nas fontes escritas, um dos alicerces para o trabalho de investigação (Corsetti, 2006), o que possibilita a interpretação das forças que perpassam a realidade social. Sendo assim e, com base nos conceitos e nas propostas de análise apresentados, relata-se na sequência quatro casos envolvendo a questão da criação de terceiros banheiros destinados aos usuários homossexuais ou travestis em espaços públicos.

\section{A Criação dos Banheiros e a Resposta dos Representantes do Movimento LGBT}

A inauguração de banheiro LGBT na quadra da escola Unidos da Tijuca, em janeiro de 2011 (Bastos, 2011), gerou polêmica e ascendeu à discussão o fato sobre o espaço e o uso comum que se faz dele. Enquanto os representantes da escola diziam acreditar estar contribuindo para a diversidade, membros representantes de associações LGBT divergiam sobre o assunto. Alguns argumentavam que o banheiro serviria para deixar gays e travestis mais à vontade, já outros argumentavam ser esta mais uma forma de discriminação. Vale destacar que há um aparente consenso nas redes sociais de que a escola de samba Unidos da Tijuca é considerada a preferida entre os gays cariocas, o que talvez tenha culminado na criação do terceiro banheiro.

O argumento da escola era o de que a demanda surgiu do próprio grupo que frequentava o banheiro masculino e não se sentia confortável com isso. O diretor de comunicação da escola apontou ainda que a ideia era evitar brincadeiras de mau gosto e mesmo constrangimentos ao grupo LGBT. De acordo com a reportagem de Mendonça (2011) foi a partir de relatos de que nem os travestis, nem os homossexuais masculinos ou femininos sentiam-se bem em usar os banheiros comuns. Por isso, surgiu a iniciativa da escola em instalar banheiros específicos para esse público. O representante da escola aponta ainda que houve a aprovação de membros da ala gay da Unidos da Tijuca.

Costa (2011) relatou que o coreógrafo da escola disse querer que o terceiro banheiro fosse transformado em um ambiente de interação para os homossexuais da escola, que pudesse ser um grande camarim para todos os homossexuais, travestis e transformistas. De acordo com a repórter, alguns sujeitos argumentaram que a criação de um banheiro exclusivo é um alívio e que existem coisas que não dá para fazer em um banheiro masculino ou feminino. A ala favorável a criação de um banheiro gay afirmou que haveria mais liberdade em um banheiro onde todos se entendem.

Contudo, contrapondo-se a esses argumentos em defesa da escola e da instalação dos banheiros, o jornalista Bastos (2011) elencou o posicionamento de um ativista que dizia que a criação de banheiros exclusivos para homossexuais é algo discriminatório. Para o ativista, a luta pela inclusão e pelos direitos iguais é afetada com a criação de mais um dispositivo de segregação. Ele acreditava que não se deveria separar para evitar o incômodo, mas sim construir espaços em que as diferenças sejam aceitas e respeitadas. O presidente do Conselho Estadual dos Direitos da População LGBT apontou ainda que, tratava-se de mais um estímulo disfarçado à homofobia e que embora pareça uma boa intenção, a criação desses espaços exclusivos pode intensificar efeitos de discriminação.

A polêmica despertada pela notícia da inauguração do terceiro banheiro na escola de samba Unidos da Tijuca talvez tenha ganhado maiores dimensões por se tratar de uma escola campeã do carnaval de 2010, bem como ser uma das organizações carnavalescas que mais aparecem na mídia carioca. Contudo, ao investigar sobre a ocorrência, encontrou-se notícias de que outras quatro 
escolas no Rio de Janeiro já têm banheiros para gays, lésbicas e transexuais. De acordo com Costa (2011) a primeira escola a instalar um banheiro gay foi a Unidos do Viradouro, no ano de 2006. Em seguida, as escolas Unidos de Vila Isabel, Porto da Pedra e Grande Rio também optaram pela criação de banheiros exclusivos para a comunidade LGBT.

Acompanhando esse movimento iniciado nas escolas de samba, outros eventos em diferentes localidades do país aderiram à criação de banheiros exclusivos. Outro caso relatado nas mídias eletrônicas foi a proposta de disponibilização de banheiros específicos para gays em uma feira agropecuária no estado do Acre (Machado, 2012). A ideia partiu do governo estadual, que foi prontamente criticado pelo presidente da Associação de Homossexuais do Acre (AHAC), o qual argumentou não aceitar a criação desses espaços específicos por ser contra qualquer forma de homofobia internalizada. Para ele, a criação de banheiros exclusivos é uma forma de ridicularização da diversidade e que envergonha saber que a iniciativa parte do poder público.

Para Germano Marino (2012) há uma grande controvérsia entre a luta dos direitos humanos LGBT e a criação dos banheiros ou qualquer outra forma de distinção de espaços públicos destinados a esse ou aquele cidadão. Ele aponta que esse tipo de discussão resultaria em mais discriminação e alimentaria o estigma contra os homossexuais. Seu argumento é de que os espaços devem ser os mesmos, tanto para heterossexuais quanto para homossexuais. Para ele, quem deve decidir qual banheiro frequentar é o próprio indivíduo e o dever do Estado é o de fazer campanhas de conscientização e aceitação, respeitando das identidades de gênero e não o de promover ainda mais formas de segregação.

Para o presidente da AHAC a diversidade não deve ser um fator separatista ou segmentador entre os indivíduos. Ter um banheiro gay é abrir uma porta para aumentar o estranhamento em relação aos homossexuais, como se tratando de pessoas tão diferentes que merecem e necessitam de espaços exclusivos e isolados. O que se deve colocar em pauta, segundo Marino (2012), é a efetivação de direitos iguais e não específicos para essa ou aquela comunidade. O ativista é ainda mais enfático ao apontar que é necessário pensar em direitos humanos e não em direitos hétero ou homossexuais.

Em resposta aos questionamentos e descontentamentos da comunidade LGBT, os organizadores da Feira Agropecuária do Acre argumentaram que embora tenham considerado a construção dos banheiros exclusivos para homossexuais, tiveram o cuidado de consultar representantes da referida classe, o que os fez recuar diante das reclamações e da insatisfação perante a proposta. Os representantes do evento argumentaram ainda que houve precipitação em tratar o assunto publicamente, pois não intencionavam causar polêmica e que, diante da recusa dos interessados, os banheiros não seriam construídos, como efetivamente não foram (Machado, 2012).

Contribuindo para a discussão sobre a criação de banheiros gays em eventos populares, o diretor de uma escola no interior do Estado do Paraná também resolveu criar banheiros especificamente destinados ao uso de adolescentes homossexuais. Como é de se esperar em assuntos que envolvam adolescentes, pais e família, o assunto gerou conflitos ainda mais intensos que nos casos referidos anteriormente. De acordo com matéria veiculada no G1, em 08 de fevereiro de 2012, o diretor do Colégio Estadual Vicente Rijo, na cidade de Londrina, no Estado do Paraná, criou um banheiro que, segundo ele, é opcional, alternativo e não exclusivo ao uso dos alunos homossexuais. Embora a iniciativa da direção já tivesse dois anos, somente no início de 2012 se tornou pública, o que levou à Associação Brasileira de Lésbicas, Gays, Bissexuais, Travestis e Transexuais (AGLBT) a desaprovar a medida e encaminhar um ofício à Secretaria de Educação do Estado do Paraná.

O diretor, no entanto, argumentou que os alunos têm a opção de usar um banheiro alternativo e que a necessidade de criação desse espaço foi percebida quando dois alunos reclamaram por sofrer constrangimentos no sanitário masculino e que, após a decisão ser aprovada pelo Conselho Escolar, que também informado de outras situações pontuais, decidiu transformar o banheiro dos professores em uma alternativa para os alunos que sentiam-se deslocados no banheiro convencional (G1, 2012). De acordo com a matéria, um estudante de 17 anos relatou que os meninos ficavam olhando com cara feia quando ele usava o banheiro e que, em 2011, uma inspetora do colégio o levou para a direção quando o flagrou dentro do banheiro feminino. Ademais, houve uma solicitação para que ele usasse o banheiro dos professores, para evitar constrangimentos para as meninas.

De acordo com o G1, o diretor informou que o único objetivo da escola é a educação e que na avaliação dos professores e da direção da escola a medida não era discriminatória e nem mesmo visava o isolamento dos alunos homossexuais. No entanto, o presidente da AGLBT não pareceu compartilhar da opinião da direção da escola e disse que mesmo que a intenção tenha sido beneficiar ou preservar os homossexuais, a atitude reflete uma solução simplista que, ao não se 
aprofundar na questão do respeito e do direito, a diferença apenas promove ainda mais a segregação e o preconceito.

A matéria veiculada pelo G1 apontou ainda que ao ser questionado sobre os banheiros alternativos, o secretário estadual de educação, Flávio Arns, disse não ter conhecimento sobre a criação de banheiros exclusivos e que essa se trata de uma questão desnecessária, que deve ser vista com cautela, pois o que se deve criar na escola é um clima de respeito à diversidade. 0 envio de um ofício a Secretaria Estadual de Educação foi uma tentativa de evitar que a ação se proliferasse e ganhasse espaço em outras escolas da rede pública ou privada.

Nessa sequência de acontecimentos envolvendo a questão dos banheiros, em julho de 2012, o vereador Carlos Apolinário propôs um projeto de lei que objetivava a criação de banheiros unissex em espaços públicos da cidade de São Paulo. A ideia do vereador é a de garantir a homens e mulheres o direito de encontrarem nos banheiros apenas pessoas de seu próprio sexo e que o banheiro unissex seria então usado por gays, lésbicas, bissexuais ou mesmo heterossexuais que preferissem utilizá-lo (Pinho, 2012). A iniciativa do vereador ocorreu após o famoso incidente com o cartunista Laerte, que ao usar um banheiro feminino, foi repreendido imediatamente após entrar no ambiente onde havia uma mulher e uma criança.

Para o vereador, seu projeto visa à diminuição da chance desse tipo de constrangimento ocorrer com maior frequência. Segundo ele, instalar os banheiros unissex em shoppings centers, supermercados, restaurantes, cinemas e locais de diversões na cidade de São Paulo evitaria que um homem que insiste em dizer que se sente mulher tivesse o direito de entrar no banheiro feminino, o que ele acredita constranger as pessoas (Pinho, 2012). De acordo com o repórter que veiculou a notícia sobre o projeto de lei proposto por Apolinário, a lei obrigaria os estabelecimentos a criarem um terceiro banheiro. Não é de se espantar que esse tipo de comentário saia da boca de uma pessoa que outrora apresentou outro projeto em sentido semelhante, o da criação do Dia do Orgulho Heterossexual. E que, ademais, faz comentários sobre a falta de tranquilidade de esposas, mães e filhas ao terem que frequentar espaços compartilhados por homossexuais ou homens indefinidos.

Esses relatos, em um primeiro momento, parecem descrições corriqueiras de acontecimentos de pouca ou nenhuma importância, mas podem revelar nuances de crueldade, discriminação e violência. O grau aparente de naturalização e simplicidade das ocorrências pode ainda mascarar os verdadeiros sentidos envolvendo a criação ou mesmo evocação de espaços de segregação. Nesse sentido, explora-se a seguir alguns dos traços observados a partir dos relatos feitos até aqui e das discussões sobre violência e poder simbólico. Desenvolve-se ainda, uma breve discussão sobre a criação dos banheiros para lésbicas, gays, bissexuais e transgêneros e o exercício do poder nesses lugares que, em princípio, poderiam corroborar para o conceito de Augé (1994).

\section{Lugar de Segregação ou Direito Adquirido?}

O primeiro passo para as análises realizadas foi considerar a definição de não lugar (Augé, 1994), que seria então aplicada a lugares de passagem como seria o caso dos banheiros. No entanto, um questionamento pareceu plausível: se os banheiros são lugares neutros e com caráter apenas utilitarista, porque tanta discussão envolta na criação de um terceiro banheiro? Pois bem, isso pareceu confirmar a discordância com a proposta de Augé (1994). A temática da instalação desses espaços é contrária a ideia de que os lugares, no sentido antropológico, seriam apenas aqueles escolhidos por nossos ancestrais sociais para que pudéssemos nos relacionar com o mundo a partir de padrões e regras previamente estabelecidos. Essa contradição está em um simples aspecto de toda a situação, o fato de que ninguém escolhe um banheiro para socializar-se, mas eles estão aí e pessoas se encontram neles o tempo todo, socializam, tecem pequenas conversas ou interagem de alguma forma. A própria separação que se faz entre banheiro feminino e masculino já diz muito sobre nossa condição social, sobre a separação entre homens e mulheres, sobre o que é direito e dever de um e de outro. Mesmo em ambientes como os banheiros, a existência, os modos, os costumes e as crenças fazem sentido e promovem processos identitários relacionais e históricos.

Se os banheiros pudessem ser considerados lugares de passagem apenas, em que não houvesse espaço para subjetivações e interações sociais, por quê uma senhora se incomodaria tanto com o fato de um crossdresser utilizar o mesmo banheiro que ela? A transmissão ou reificação de códigos em banheiros é um fato da vida social, e esses lugares têm sido importantes pontos de partida para a discussão da legitimidade de certas regras estabelecidas, porém, não compartilhadas. Seriam os banheiros lugares em que a construção de identidades seria possível? O comentário do coreógrafo da escola de Samba Unidos da Tijuca parece expressar bem essa possibilidade, pois, ao afirmar que os banheiros LGBT seriam transformados em camarins para a comunidade gay, ele aponta a probabilidade de construção e um espaço social dentro de um singelo banheiro. 
Outro aspecto que parece ir ao desencontro da noção de não lugar é que esses espaços estariam isentos de regras de convívio social, o que parece não ser uma verdade em se tratando da instalação de banheiros específicos para a comunidade LGBT. O fato de promover a segregação entre os indivíduos, mesmo sob o discurso de preservação e proteção da integridade, seja de hétero ou homossexuais, é uma forma de inscrição objetiva que busca delimitar a constituição dos sujeitos, imponde-lhes fronteiras e marcando relações entre indivíduos e grupos. O momento em que vivemos demonstra que a insistência para a criação desses espaços de segregação constitui-se como uma construção histórica que visa disseminar regras e costumes sociais entendidos por alguns - que detém algum tipo de poder - como os mais adequados em nome de uma ordem ilusória.

Ora, pode-se observar que não parece haver espaço para a efemeridade, transitoriedade ou solidão. Se nem mesmo os banheiros de uso compartilhado podem ser entendidos como um lugar de individualização, haveria na contemporaneidade um espaço livre de contradições e complexidades, em que ideais totalitaristas não proliferassem sistemas de interpretação e imposição de regras aos sujeitos? Conclui-se que não, pois a percepção do tempo e o uso e disposição que fazemos dele pode ser ressignificada em qualquer lugar em que circulem pessoas. Entende-se que qualquer lugar onde há pessoas pode ser um espaço propício para que ocorram manifestações de sentido e de libertação das convenções, bem como não parece haver um lugar totalmente livre de questões sociais.

A polêmica acerca da criação dos banheiros exclusivos para a comunidade LGBT parece retratar nossa submersão na cultura e nossa sujeição às regras que nos são impostas. Parece que não somos livres nem mesmo para usar um banheiro. As convenções e limitações instituídas nos lugares têm sido levadas aos locais menos prováveis e demonstrado ser quase impossível de qualquer neutralidade. Somos seres políticos, mesmo ao nos dirigir a esse ou àquele banheiro. Parece irônico, mas ao contrário das afirmações de Augé (1994), interagimos em qualquer que seja o lugar. Deixamos sempre um pouco de nós e parecemos estar sempre aptos a legitimar essa ou aquela regra. Criamos e recriamos lugares, permitimos sim que cada lugar seja a expressão de uma época, de uma cultura ou de valores socialmente compartilhados. Porém, fazemos isso sempre pautados em sentido e reconhecimento de nossa condição, seja ela qual for.

Mesmo em lugares tão aparentemente instrumentais percebem-se ações de violência simbólica. Essa forma tênue e absurda dos modos de dominação explora o caráter arbitrário e mágico das representações coletivas, seja em qual for o ambiente. É a partir da lógica de funcionamento das relações sociais e da inteligibilidade acerca das estruturas objetivas e subjetivas que situações de violência são criadas e exercidas diariamente, nas circunstâncias mais comuns e corriqueiras. Aqueles que se encontram em posições que facilitam a tirania tomam posse de estratégias de dominação e veiculam suas crenças por meio de dispositivos que visam conservar e perpetuar o status quo, isto é, buscam manter as posições e os princípios de dominação vigentes. O caso dos banheiros é um exemplo claro de violência simbólica, uma violência mascarada sob o discurso de inclusão. Trata-se de uma situação de violência difícil de ser combatida, uma vez que se pauta em falsos princípios protecionistas, que velam a real intenção, o que dificulta em demasia qualquer forma de contestação.

Exceto em situações declaradas - como é o caso do vereador paulistano que, apregoa a criação dos banheiros sob o discurso de preservar as esposas, mães e filhas do encontro com pessoas diferentes e, (consideradas por ele), como sendo indignas de compartilhar os mesmos recintos que as pessoas de bem. As ações relativas à instalação de banheiros exclusivos parecem se elaborar pautando em circunstâncias que visam não esbarrar na reprovação coletiva. O processo é conduzido de tal forma que os detentores do poder de criar e definir formas de conduta engajam-se cautelosamente, dissimulando as reais intenções e articulando ações que se travestem de benéficas. Toda a atenção reclamada à criação dos banheiros na escola de samba, por exemplo, demonstra a articulação para promover o fato como algo não arbitrário e muito menos ilegítimo.

Contudo, é claro que no caso específico da utilização do banheiro dos professores, como uma opção para os alunos homossexuais, existem particularidades. Há nuances não observadas nos demais casos aqui expostos. Talvez, exclusivamente nesse caso, haja uma intenção real em preservar esse ou aquele aluno, mas a questão que se coloca é até que ponto os alunos com diferentes orientações sexuais estão, de fato, sendo protegidos. Não estariam esses alunos sendo ainda mais expostos ao optarem por usar o banheiro especial? Essa atitude da direção não estaria caminhando para o retrocesso? Após abolirem as salas especiais, estariam, agora, instituindo os banheiros especiais? Os banheiros tornar-se-iam então aparelhos ideológicos em que se promoveria uma dinâmica social onde os grupos dominantes estariam delimitando sua autoridade, evitando conflitos e viabilizando o exercício do poder. Os banheiros para a comunidade LGBT ilustrariam então o que Foucault (2000) chamou de uma maneira perversa de dominação, em que os sistemas 
simbólicos operam sistematicamente, favorecendo o cumprimento dos interesses dos grupos dominantes.

A situação dos banheiros caracteriza ainda o que Bourdieu (2008a) define como formas sofisticadas de dominação, que elementos como a distinção ou a política (Bourdieu, 2009a, 2009c) se apropriam de políticas identitárias para proliferar a dissimulação e a distorção dos verdadeiros sentidos e valores. A dissimulação às vezes é tão articulada que sujeitos constituintes das minorias são capazes de aderirem ao que lhes é imposto sem nem mesmo notar. Apropriam-se inclusive dos discursos, reproduzindo-os de tal forma que as intenções mascaram-se e legitimam-se pela voz dos próprios reprimidos. Temos um exemplo evidente quando lemos os depoimentos de satisfação de alguns homossexuais que se declararam felizes por terem um espaço exclusivo. 0 que poucos parecem notar é o fato de que se torna cada vez mais difícil subverter, qualquer que seja a ordem, quando não se tem consciência da dominação.

Contudo, a forma mais viável para qualquer resistência parece ser a crítica e a consciência da realidade. A verdade parece constituir um dos aspectos mais relevantes para na luta contra a dominação e o exercício da violência, seja ela simbólica ou não. A problemática, no entanto, reside no fato de que para se acessar a verdade se faz necessário compreender a lógica de dominação. No caso dos banheiros, a sutileza leva a uma circunstância demasiadamente perigosa, uma vez que discursos feitos falsamente em prol do grupo prejudicado têm o papel de desmobilização dos grupos que poderiam, de alguma forma, apresentar qualquer resistência. Quando os líderes das associações representantes dos movimentos LGBT manifestam-se contrários a instalação de banheiros exclusivos, parece haver uma dicotomia entre o que é de interesse das entidades de classe e o que realmente interessa ao grupo. Isso se deve ao fato de que, de um lado, os presidentes das associações requerem direitos iguais e não espaços de segregação e, por outro lado, alguns gays e travestis demonstram-se satisfeitos com as ações adotadas por algumas organizações. Isso demonstra que nem todos estão de acordo com a arbitrariedade que envolve a instalação dos banheiros LGBT e que há aqueles que naturalizam a necessidade de segregação.

Por considerar importante a discussão acerca do tema envolvendo a dominação e violência simbólicas, discute-se aqui a necessidade de se promover a reflexão e buscar desvelar as formas mais sutis de dominação. Evocar discussões sobre as diferentes formas de exercício do poder é uma maneira de incitar algum tipo de subversão e, ao mesmo tempo, assumir a capacidade de os sujeitos sentirem, pensarem e agirem conforme e a partir do lugar em que são inseridos socialmente. A instalação de banheiros exclusivos é uma forma violenta de imposição e incorporação da ordem dominante e a extensão desse tipo de violência pode ser ainda mais cruel se pensarmos que ao apontar as diferenças, nós criamos mais e mais caminhos e justificativas para o preconceito e a segregação. O que parece haver com os indivíduos que apoiam a proposta dos banheiros exclusivos é uma espécie de submissão, tanto objetiva quanto subjetiva, que torna um assunto que poderia ser tão simples como o simples ato de defecar ou fazer xixi, torne-se uma estratégia sofisticada de dominação, capaz de apreender os indivíduos a tal ponto que promove a incorporação de uma identidade social associada a um corpo. Essa circunstância torna-se nociva, já que a limitação da compreensão de mundo - a partir de imagens - impede que se repense a ordem social e se busque por igualdade e não ações disfarçadas de inclusão.

Conforme o trabalho de Teles (2012), verificamos que no caso da instalação dos banheiros LGBT, os indivíduos têm suas crenças, valores, diferenças e anseios limitados e objetivados no real, no concreto, limitando o aprendizado de si a partir das representações de terceiros. Esse aspecto torna difícil recuperar a essência de si mesmo e dificulta a possibilidade de construção de espaços de negociação, resistência ou mudança. É preciso que se considere que segregar não contribui para a socialização ou aceitação, ao contrário, cria ainda mais dificuldades em lidar com a diferença e estabelece regras que cerceiam qualquer capacidade inventiva e amigável de conciliação e respeito. A criação de espaços diferenciados parece transmitir uma mensagem uníssona de não aceitação e estabelecimento de uma superioridade cruel, que define quem pode o que e onde. Mesmo que se trate de um simples xixi ou uma olhadela no espelho de um banheiro de uso público.

\section{Considerações Finais}

A análise sobre a criação dos banheiros LGBT não é algo simples. Há que se ter o cuidado para não cair no ostracismo de nossas próprias conviç̧ões. Trata-se de uma questão muito mais delicada do que parece, no entanto, há que se pensar sobre tudo o que está por trás de uma simples instalação de um banheiro exclusivo. Obviamente não se trata da questão física referida aos banheiros, aliás, a questão concreta é apenas uma objetivação de questões muito mais profundas. 0 que se está fazendo, no caso dos banheiros, é a instalação de ideias separatistas e preconceituosas, 
pois estão dizendo sutilmente que homossexuais e travestis não são dignos de utilizar o mesmo espaço destinado às pessoas comuns. Pior, estão dizendo que não se tratam de pessoas comuns.

É ainda de suma importância observar que são organizações expressivas as personagens no topo da temática. Não estamos tratando aqui da instalação de um banheiro gay no botequim do Zé não que isso não fosse relevante - mas estamos falando de uma famosa escola de samba, o que no Brasil representa muito, tanto em termos econômicos quanto culturais. Ou ainda de uma escola, que perpetua crenças e valores, certo e errado, convicções sociais e reprodução de práticas culturais. Estamos tratando de poder político, de um governo de Estado, ou mesmo de um político da cidade mais significativa do país. Os ideais por trás da questão dos banheiros não nos podem escapar. São políticos e organizações querendo impingir seus valores, utilizando-se de estratégias vis, porém, elaboradas, para se promoverem perante a sociedade, ao mesmo tempo em que estabelecem sua ordem e padrão moral.

Contudo, algumas limitações precisam ser apontadas. A análise feita aqui é apenas uma tentativa inicial de incitar a discussão mais aprofundada sobre a questão dos banheiros LGBT. É preciso ainda elaborar melhor o papel que os estudos organizacionais teriam mediante tais circunstâncias. Além disso, seria preciso desenvolver argumentos que pudessem esclarecer a importância do recorte adotado no presente artigo, para então situar o papel das organizações na elucidação dos direitos e da promoção da igualdade de direitos e da aceitação das diferenças.

Recomenda-se que se faça uma análise mais aprofundada sobre a questão da massificação dos discursos que se buscam legitimar em práticas arbitrárias, mas que ao mesmo tempo conclamam a voz daqueles que deveriam resistir. Uma investigação mais cuidadosa seria importante para que se pudesse revelar com mais clareza as verdadeiras intenções que perpassam a realidade social em que se encontra imbricada a questão dos banheiros. Também seria valioso que se realizasse uma investigação mais densa, ouvindo diretamente os representantes das organizações LGBT, assim como os representantes das organizações que propõem a instalação dos banheiros, bem como indivíduos heterossexuais, homossexuais e travestis, para que assim se possa acessar, mais de perto, os impactos e as impressões de sujeitos diretamente envolvidos na problemática.

\section{Referências}

Augé, M. (1994). Não lugares: introdução a uma antropologia da supermodernidade. Campinas: Papirus.

Bastos, T. (2012). Unidos da Tijuca explica porque criou banheiro gay. 180 Graus. Recuperado em 04 maio 2013, de http://180graus.com/noticias/unidos-da-tijuca-explica-porque-criou-banheiro-gay391206.html

Bourdieu, P. (2008a). A produção da crença (3 ed). Porto Alegre: Zouk.

Bourdieu, P. (2008b). Razões práticas: sobre a teoria da ação (9 ed). Campinas: Papirus.

Bourdieu, P. (2009a). O poder simbólico (12 ed). Rio de Janeiro: Bertrand Brasil.

Bourdieu, P. (2009b). Coisas ditas. São Paulo: Brasiliense.

Bourdieu, P. (2009c). A economia das trocas simbólicas (6 ed). São Paulo: Perspectiva.

Carvalho, J. M. (2005). O não lugar dos professores nos entrelugares de formação continuada.

Revista Brasileira de Educação, 28, 96-108.

Corsetti, B. (2006). Análise documental no contexto da metodologia qualitativa: uma abordagem a partir da experiência de pesquisa do Programa de Pós-Graduação em Educação da Unisinos.

UNirevista, 1(1), 32-46.

Costa, J. (2012). Banheiro para gays na quadra da Unidos da Tijuca cria polêmica. Extra. Recuperado em 01 maio 2013, de http://extra.globo.com/noticias/carnaval/banheiro-para-gays-na-quadra-daunidos-da-tijuca-cria-polemica-813163.html

Foucault, M. (2000). Vigiar e punir. história da violência nas prisões (26 ed). Petrópolis: Vozes.

G1 (2012). Diretor cria banheiro alternativo para homossexual em colégio de Londrina. Recuperado em 7 maio 2013, de http://g1.globo.com/pr/ parana/noticia/2012/02/diretor-cria-banheiro-exclusivopara-homossexual-em-colegio-de-londrina.html

Lüdke, M., \& André, M. E. D. A. (1986). Pesquisa em educação: abordagens qualitativas. São Paulo: EPU. 
Machado, A. (2012). Homossexuais recusam banheiros exclusivos em Feira Agropecuária. Terra Magazine. Recuperado em 5 maio 2013, de http://terramagazine.terra.com.br/blogdaamazonia/blog/2012/07/16/homossexuais-recusambanheiros-exclusivos-em-feira-agropecuaria/

Marino. M. (2012). Movimento LGBT expressa descontentamento com possibilidade de banheiro gay. Elos LGBT. Recuperado em 6 maio 2013, de http://www.eloslgbt.org.br/2012/07/ movimento-lgbtexpressa.html

Mendes, F. C. (2011). Ações educativas na polícia civil: o "não-lugar" do menor infrator. Revista de Educação, Ciência e Cultura, 16(2), 145-156.

Mendonça, A. V. (2011). Banheiro gay é inaugurado com pompa na quadra da Unidos da Tijuca. G1. Recuperado em 1 maio 2013, de http://g1.globo.com/carnaval/2011/noticia/2011/01/banheiro-gay-einaugurado-com-pompa-na-quadra-da-unidos-da-tijuca.html

Minayo, M. C. S. (1994). Ciência, técnica e arte: o desafio da pesquisa social. In M. C. S. Minayo (Org.). Pesquisa social: teoria método e criatividade (3 ed) (pp. 9-28). Petrópolis: Vozes.

Pinho, M. (2012). Vereador apresenta projeto de lei para a criação de banheiros para gays em SP. Recuperado em 7 maio 2013, de http://g1.globo.com/sao-paulo/noticia/2012/02/vereador-apresentaprojeto-de-lei-para-criacao-de-banhei ros-para-gays-em-sp.html

Santos, A. R. (2000). Metodologia científica: a construção do conhecimento (3 ed). Rio de Janeiro: DP\&A.

Silva, C. G., \& Brasil, L. A. A. (2010). Personagem e não lugar: identidades em construção. Anais da Mostra de Pesquisa da Pós-Graduação, Porto Alegre, RS, Brasil, V.

Teles, N. (2012). O não lugar do feminino: reflexões sobre a representação objectual da mulher. Anais da Conferência Internacional do IESE, Maputo, Moçambique, III.

Vieira, M. M. F. (2004). Por uma boa pesquisa (qualitativa) em administração. In M. M. F. Vieira, \& D. M. Zouain (Org.). Pesquisa qualitativa em administração (pp. 13-28). Rio de Janeiro: FGV. 